\title{
A Study on the Value of Chinese Traditional Sport Culture in the Process of Cross - cultural Adaptation of International Students
}

\author{
Dandan $\mathrm{Ma}$ \\ Qujing Normal Univiersity, Qujing, China \\ 87481793@qq.com
} Keywords: Chinese traditional sports culture; Foreign students; Cross - cultural adaptation; Value
research

\begin{abstract}
The problem of cross-cultural adaptation of international students has been paid more and more attention with the increase of the number of foreign students coming to China, which is caused by many aspects. The difference between Chinese and foreign cultures is one of the main causes of this problem. This paper analyzes the connotation and essence of Chinese traditional sports culture from the perspective of Chinese traditional sports culture and looks for the logical connection between it and the problem of cross-cultural adaptation of foreign students and demonstrates the value of Chinese traditional sports culture in the process of cross-cultural adaptation of international students. It is suggested that in the future teaching of foreign students, more teaching content related to the traditional Chinese sports culture can be integrated to promote the essence of traditional Chinese sports, enhance the soft power of Chinese culture, and reshape power image.
\end{abstract}

\section{Introduction}

With the strengthening of economic strength and the upgrading of international status, China has attracted more and more attention on the world stage. The study of Chinese or to study in China also will become a world trend. According to the latest statistics of the Ministry of Education, by 2015, foreign students have reached 397,635 , an increase of $5.46 \%$ than 2014 , sources of students are from five continents of the world. Although these students from all over the world have different cultural backgrounds and different languages, after they become International students in China, they are faced with the same problem: cross-cultural adaptation. For people living abroad or studying abroad, cross-cultural adaptation process is tortuous and difficult, because the "cultural shock" is inevitable. For the individuals, the main methods to overcome the impact of "cultural shock" are psychological adjustment and active integration into the local culture, while for institutions or universities accepting international students, in addition to arrangements for daily language teaching, appropriate integration into the Chinese traditional culture teaching can also has a positive impact on cross-cultural adaptation. Traditional Chinese sports culture is an important part of Chinese traditional culture. Compared with other types of traditional culture, sports culture has characteristics of direct communication, high acceptance and strong maneuverability. However, due to many reasons, people always lack understanding of the value of traditional sports culture and cultural essence, resulting in many colleges and universities' neglect of introduction of the traditional sports culture in teaching the traditional culture, not paying enough attention to the role of traditional sports culture. Therefore it is necessary to explore its value in the cross-cultural adaptation process of international students.

\section{Influencing Factors of Cross - cultural Adaptation of International Students}

The original objects of study on intercultural adaptation are expatriates, but with the further development of education internationalization, scholars find that foreign students, like those expatriates, will face a lot of shocks and changes from one culture to another, such as changes in living environment, eating habits and living habits, impact of values and the mother culture and so on. If the above problems are not handled properly, it is very likely that foreign students and 
expatriates will have physical illness or be sick in hospital, but there are many psychological problems: they are not happy with their life and studying abroad, and even there will be negative emotions such as anxiety and depression over time.

On the cross-cultural adaptation of international students, many scholars have some research results from different professional point of view. The author will perform elaboration and analysis based on scholars' study from the two aspects of external factors and internal factors.

\section{The Main External Factors Affecting the Cross-cultural Adaptation of International Students.}

Values. The construction of a person's values and his/her growth experience are inseparable from the mother culture. Through survey, some scholars find that many foreign students still cannot agree with or accept some of China's values, because in their growth experience and mother culture, some of their basic morality and ideas of their own countries have been instilled in their minds from their childhood, which have become their behavior norms and parenting habits [1]. When they enter a new culture and find that the behavior pattern of the locals is different from their own and cannot receive a reasonable explanation with their own values, they will have difficulties in adaptation. China has unique history and culture, making the Chinese people also form a set of unique values different from other countries or regions, such as the "differential pattern" mentioned by teacher Fei Xiaotong in the "Native China". In short, the differential pattern refers to the relative network similar to concentric ripple diffused outward by each person regarding their own as the center [2]. In reality, the performance is "inside and outside are different", especially in the service industry, for their acquaintances, people will show every consideration to them, but for the average customers, performance is more indifferent. Another value the international students cannot understand is the Chinese people's group concept. Most Chinese people have a strong group concept, thinking that people are living in a variety of "groups", and cannot exist in isolation. So when a lot of international students are asked to do collective action by schools, they do not understand at all. These "unique features" are one of the reasons why many adaptation problems arise.

Support System. Support system mainly refers to support of a variety of resources to a person, such as material support (money, living supplies, and etc.), emotional support (kinship, friendship or love) and other support (psychological counseling, social activities, school curricula, and etc.). More comprehensive support can help students overcome stress, anxiety, helplessness and loneliness. But the reality is barely satisfactory, especially in emotional support and other support. Taking friendship support in emotional support as a an example, if students can make friends in a foreign country, it is a very happy thing, but in the process of getting along with Chinese friends, Chinese friends" "excessive care", "direct expression" and "inquiring about private information" and other habits often cannot constitute a good support system, and sometimes even become counterproductive. In other support systems, most of the universities of accepting international students do not specifically set up psychological counseling courses for foreign students, and most of the courses are mainly offered by the language teaching, cultural experience courses have begun to be valued in recent years, but the effect of teaching and acceptance level are still unknown.

The Distance between Mother Culture and Chinese Culture. In general, students from Asian countries such as Japan, South Korea, and Southeast Asia are better than those from America, Europe and Africa in cross-cultural adaptation. Because of the geopolitical relationship, the mother culture of these countries in Asia can be traced back to Chinese traditional culture more or less, and many of the preserved folk or traditional festivals are inextricably linked with the Chinese similar culture. While the countries from America, Europe and Africa are too far from China in the geographical relationship, so there is no similar or cross in the mother culture. It can be said that the closer the distance between the mother culture and Chinese culture is, the greater cross-cultural adaptation degree and acceptance of Chinese culture will be, on the contrary, the greater the distance is, the smaller the adaptation degree and acceptance will be, and the greater the cultural impact it will face will be. 


\section{The Main Internal Factors that Affect the Cross-cultural Adaptation of International Students}

Ethnocentrism. Ethnocentrism, also known as national pride, is prevalent in every culture and is the core embodying ethnic or national self-identity and cohesion. However, when this pride appears in the process of cross-cultural adaptation, it is reflected in raising the motherland culture and then conflicting, disliking or belittling the culture of other countries in the subconscious. For international students, if there is such mentality, he/she cannot well accept the environment and the people around, and is likely to think that the current country he/she stays is very poor, people are very unfriendly and bad-mannered, and will erect a high wall between themselves and the outside.

Stereotypes and Racial Prejudice. Before coming to China, many international students had seen or heard many stereotypes about China through the local media or social networks, for example, they think that China is militaristic and is the threat of neighboring countries; that China only knows copying and imitation, without its own ideas; that the Chinese people are poor, cannot afford to eat western food, taking the KFC as a gluttonous feast; or that the Chinese is the sick man of East Asia, achieving sports medals by eating stimulants ...... there are various reasons for these prejudices, but in cross-cultural adaptation, if holding a deeper stereotype and racial discrimination, even if the facts the international students see have contrasts with his previous understanding, he is also likely to think it is not his own problem, or even will exacerbate prejudice, and hinder recognition of the new culture.

Language Proficiency and other Factors. If an international student has a certain Chinese foundation, then as his language proficiency increases, his cross-cultural adaptability will also be enhanced. Because language is a communication tool, skilled use of language tool can enhance the confidence of foreign students and improve their well-being in the exotic cultural circle. In addition, gender, age, educational background, personality and other reasons are internal factors affecting the cross-cultural adaptation of foreign students.

\section{The Connotation and Essence of Chinese Traditional Sports Culture}

As rooted in the deep soil of traditional Chinese culture, the Chinese traditional sports culture is deeply influenced by Confucianism or Taoism and has formed a set of complete philosophical system. Its connotation and essence are mainly reflected in the following aspects:

Focusing on "Harmony" and "Whole". Different from the Western sports spirit which emphasizes "higher, faster, stronger", Chinese traditional sports spirit advocates "harmony", "whole" and "unity of heaven and man", such as traditional folk sporting events of lion dance and dragon boat race. Although they originate from the traditional ritual or harvest celebration and other folk customs activities, but their essence embodies thought of "harmony" and "whole", because only with harmonious actions and tacit understanding, two people can show a vivid lion; And only with uniform action and going forward together, the dragon boat can reach first, so does the traditional martial art of shadowboxing, whose intention is to use people's actions to reflect the philosophical thought of "unity of heaven and man", to pay attention to internal and external harmony and unity own mind and body, and think that the pursuit of Heaven is the human's part and knowing themselves equals to knowing the Heaven.

Advocating Morality and Respecting the Ritual. "Ritual" is one of the essences of Confucianism, and Chinese traditional sports are so profoundly influenced by ethical thought, and has become a method for moral education, cultivate sentiment and cultivate etiquette. Such as holding fist salute in martial arts, which asks making a fist with the right hand, meaning emphasizing martial arts; buckling of thumb of left palm, meaning being modest to ask each other, and never being arrogant; making a fist with left hand, implying advocating morality and making friends with martial arts; holding four fingers of the left palm together, meaning forging ahead in unity of martial arts circles; bending round two arms, meaning the harmony and unity of martial arts circles in the world[4]. A seemingly very simple movement of martial arts contains so much ritual content, which is used to regulate the words and deeds the martial arts artists. Superficially the "ritual" in the traditional sports culture is to regulate the code of conduct, but its essence is to 
internalize the consciousness of people and cultivate moral sentiments.

Unification of Form and Spirit, and Unity of the Surface and Inner. Compared with the Western sports culture, "material" components in Chinese traditional sports culture are relatively fewer. The purpose of sports is not all for competition and surpassing, and more is to achieve the "unification of form and spirit, and unity of the surface and inner", that is, to achieve a combination of body and spirit. "Huai Nan Tzu- the original morality training" pointed out: "body is the house of life; vitality is the driving force of life; and spirit is the master of life, of which one is lost, then the other two will also be damaged"[5]. The meaning of this sentence is that visible body is the house (carrier) of life, the invisible "vitality" is the driving force of life; and the spirit is the master of life; the three parts are as a whole, performing their own duties, and if one is damaged, the other two will also be damaged. It is thought that the phenomenon of life is a unified movement state of the body and the spirit [6]. It can be known that the Chinese traditional sports culture promotes the power of spirit, for example, eight trigrams boxing and Tai Chi pursue unity of body and spirit to achieve physical and psychological harmony and unity.

\section{The Value embodiment of Chinese traditional sports culture in the process of cross - cultural adaptation of international students}

Help to Understand Chinese Values. Through the above discussion, we can learn many cross-cultural adaptation problems, the root causes can be interpreted as the differences between Chinese and Western values, such as the exclusion of group-based awareness in Chinese culture and individual-based consciousness in Western culture. However, if allowing students to understand or experience some traditional Chinese sports, such as dragon dance, lion dance or dragon boat, they will find the limited power of the individual and the strong cohesion of the collective forces. Under such circumstances, they can realize that they are not isolated but have a very close relationship with other people, and will understand some of Chinese people's values and behavior styles putting the group first.

Enrich the Kernel of the Support System. As mentioned above, if there is a more comprehensive support system, international students' cross-cultural adaptation process will be smoother. At present, many colleges and universities have opened the corresponding cultural courses for international students, such as calligraphy, paper cutting, painting and even Peking Opera, Tai Chi and martial arts courses. But most of the cultural courses teach only how to do, but do not say why, resulting in that students know how to do but do not understand. Taking Tai Chi and martial arts as examples, although there are some difficulties in explaining the deep historical and cultural background behind Tai Chi and martial arts for students in China who have limited Chinese proficiency, you can explain in English so that they can understand why many movements in Taiji like "round"; and why holding fist salute even before confrontation of martial arts competition is performed, for these core knowledge profoundly reflecting the traditional sports culture and the Chinese etiquette should be known and understood by the students. In addition, the Chinese traditional sports culture is not only reflected in the Tai Chi and martial arts, courses of eight trigrams boxing and five-animal boxing can be set up, and even mahjong can be taught to allow students to appreciate the philosophical wisdom of Chinese traditional culture.

Change the Rigid Impact on China. According to psychological research, most of the stereotypes are negative and often "over-generalized", that is, "a pole kills all persons on a boat". For example, international students often see the local media reported that the Chinese people's physical quality is not good before they come to China, or compared with boxing and other sports, Chinese martial arts is ctokenistic gesture. Then when they come to China, they will spontaneously think that all the Chinese people are "weak" and Chinese martial arts are "virtual". So how to change the stereotype? The most direct and effective method is close contact and intuitive experience. Sports culture in the dissemination has characteristics of strong intuition and maneuverability. In addition to the need to explain the deep-seated sports ideas, at the other time, requirements of the language are few, so international students should get more contact with classmates or teachers who love exercise and sports, make friends with those with good physical 
fitness, and a Taiji and boxing "contest" can be arranged to let them intuitively feel the true meaning of "conquering the unyielding with the yielding", which can gradually change some of the wrong stereotypes, and promote further understanding of China.

Alleviate Negative Psychological Problems of International Students. In the process of cross-cultural adaptation, the physical maladjustment of international students can be resolved accordingly through medical treatment or seeing a doctor, but how to solve anxiety, depression and other psychological problems? China's traditional sports culture stresses that "adjustment of the mind", that is, regulating mental activity. Many traditional sporting events need "meditation". Also taking Tai Chi as an example, keeping quietness is the core of traditional tai chi training, which is a quality that Tai Chi practitioners must be trained. Tai Chi from the beginning is a dynamic and a static conversion process. If international students can learn Tai Chi, and grasp well the "keeping static" ability to learn to adjust the inner waves and negative emotions, then it will undoubtedly reduce the "cultural shock" impact furthest.

\section{Conclusion}

Chinese traditional sports culture is not only the cultural treasures of the Chinese nation but also the precious spiritual wealth left by historical sedimentation. As mentioned above, it is functionally closely related to the cultural adaptation of foreign students, which can help students overcome the discomfort in the process of studying abroad and face the impact of culture. In practice, it can expand the teaching content of traditional Chinese culture, and enrich cultural support system; in cultural output, it can carry forward the essence of traditional Chinese sports, enhance the soft power of Chinese culture, enrich the form and core of civil diplomacy, and reshape the image of the big country.

\section{Acknowledgements:}

Supported by the Youth Foundation of Qujing Normal University (Grant No.2015QN014).

\section{Reference}

[1] M Wan: Modern Educational Science, (2008) No.6, p.19.

[2] X.T Fei: Local China (Joint Bookstore, Beijing 1985).

[3] Y Cai: Journal of Zhuzhou Teachers College, (2007) No.12, p.5.

[4] J Zhang: Research on Confucianism and Traditional Chinese Sports Etiquette Culture (MS. Qufu Normal University, China 2009), p.35.

[5] A Liu, etc: Huai Nan Tzu (Guangzhou Publishing House, Guangzhou 2006).

[6] S.Y Xia, Z Xiao: Journal of Beijing Sport University,(2016)No.29, p.6.

[7] G.X Zhu: Research on Cross-cultural Adaptation College International Students in China (PH.D, East China Normal University, China 2011), p.65.

[8] X.Q Chen: Journal of Gannan Teachers College, (2013) No.4, p.48.

[9] X.C Guo: Intercultural Communication Study from the Perspective of Cultural Identity (PH.D, Shanghai International Studies University, China 2012), p.18.

[10]H.G Yang: Research on Cross-cultural Adaptation of International Students in China (PH.D, East China Normal University, China 2005), p.69. 